\title{
HEMOVIGILÂNCIA E A ATUAÇÃO DA ENFERMAGEM EM PROJETO DE EXTENSÃO: RELATO DE EXPERIÊNCIA
}

\author{
ARTIGO ORIGINAL \\ CARNEIRO, Shayanna Mickaela Duque ${ }^{1}$
}

LIMA, Maria Juraci de Oliveira ${ }^{2}$

CARNEIRO, Shayanna Mickaela Duque. LIMA, Maria Juraci de Oliveira. Hemovigilância e a atuação da enfermagem em projeto de extensão: Relato de experiência. Revista Científica Multidisciplinar Núcleo do Conhecimento. Ano 05, Ed. 01, Vol. 09, pp. 117-136. Janeiro de 2020. ISSN: 2448-0959, Link de acesso: https://www.nucleodoconhecimento.com.br/saude/hemovigilancia

\section{RESUMO}

Objetivo: relatar as práticas vivenciadas pela acadêmica de enfermagem durante sua participação no projeto de extensão com foco em Hemovigilância. Método: estudo descritivo, tipo relato de experiência, onde o transcurso do projeto é descrito por meio de tópicos, compreendido entre outubro de 2018 a maio de 2019. Resultados: o projeto desenvolve -se com a finalidade de busca permanente na qualidade da assistência em hemoterapia através do fortalecimento da Hemovigilância no complexo da Universidade Federal do Rio Grande do Norte. Conclusão: entende-se que a construção de uma política de desenvolvimento instrucional atendendo as recomendações da Agência Nacional de Vigilância Sanitária, a realização de treinamentos periódicos, checklist, fluxogramas, criação de protocolos operacionais, entre outros, consolidam o papel da equipe multiprofissional quanto a hemovigilância.

\footnotetext{
${ }_{1}^{1}$ Graduanda em Enfermagem, Centro Universitário do Rio Grande do Norte/UNIRN.

${ }^{2}$ Enfermeira, Especialista em Enfermagem do Trabalho, Faculdade Metropolitana de Ciências e Tecnologias/FAMEC.
} 
Palavras-chave: transfusão sanguínea, reação transfusional, educação

em enfermagem, notificação, hemoterapia.

\section{INTRODUÇÃO}

A terapêutica transfusional é uma modalidade assistencial realizada de modo total onde o elemento transfundido é o sangue ou parcialmente através de sua fragmentação resultando os hemocomponentes. O processo de Transfusão Sanguínea - TS familiariza os antígenos do doador, sejam eles de membranas celulares ou plasmáticos, com os anticorpos do receptor por via endovenosa. ${ }^{1}$

As situações que condicionam os pacientes a serem submetidos a esta forma de tratamento são, na maioria das vezes, alterações hematológicas resultantes de patologias, intervenções cirúrgicas e emergências que possam repercutir em considerável perda sanguínea. ${ }^{2}$

Conforme Manual Técnico de Hemovigilância ${ }^{3}$ a transfusão sanguínea embora seja uma conduta assistencial e necessária que promove benefícios imprescindíveis ao restabelecimento da saúde aos pacientes, possui efeitos adversos semelhantes à terapia medicamentosa, podendo ocorrer tanto no receptor como no doador que, por sua vez condicionam repercussões hemodinâmicas indesejáveis.

Para todos os procedimentos que envolvem a substância sangue é imprescindível cautela e o seguimento fidedigno de cuidados em todas as suas etapas. Mas, ainda assim, não isenta a possibilidade de complicações que configuram a ocorrência de Reações Transfusionais - RTs. ${ }^{4}$

A assistência ao paciente submetido a TS é realizada por equipe multiprofissional detentora de competência técnica e científica para prevenção e identificação precoce de eventos adversos, envolvidos pelo princípio da responsabilidade nas condutas relacionadas à segurança em hemoterapia, bem como nas notificações aos órgãos competentes. E dentro dessa equipe tem notoriedade a atuação do enfermeiro, profissional que está na linha de frente do cuidado initerruptamente $24 \mathrm{~h}$ todos os dias, 
devendo estar apto para a devida intervenção diante das RTs e validação dos benefícios esperados desse tratamento. ${ }^{5}$

Os profissionais de enfermagem estão respaldados legalmente para assistir os indivíduos com indicação de realização da TS e garantir a segurança em todos os aspectos intrínsecos a essa terapêutica, mediante Resolução do COFEN № 0511/2016 que dispõe sobre a atuação de Enfermeiros e Técnicos de Enfermagem em Hemoterapia, em que sistematiza as condutas de cada categoria e determina que os conselhos façam cumprir com segurança, todos os procedimentos partindo da coleta, armazenamento, administração, controle de qualidade e outras atividades anexas a esta Resolução. ${ }^{6}$

Portanto, a Hemovigilância é definida como o conjunto de procedimentos de vigilância que abrange todo o ciclo do sangue, com o objetivo de obter e disponibilizar informações sobre eventos adversos ocorridos nas diferentes etapas a fim de prevenir o aparecimento ou recorrência, melhorar a qualidade dos processos, produtos, aumentar a segurança do doador e do receptor. ${ }^{7}$ Contudo para conquistá-la, uma metodologia no processo por meio de causa e consequência deve ser estabelecida, englobando todos os profissionais envolvidos desde a capitação de possíveis doadores à transfusão propriamente dita. ${ }^{8}$

Os benefícios da hemovigilância não caracterizam apenas a diminuição da frequência e gravidade dos eventos adversos, mas também aconselha as autoridades de saúde, promove a pesquisa, treinamentos, criação de bancos de dados reais e interfere diretamente na melhora da confiança da população quanto ao processo. $O$ início de sua implementação ocorreu na França e no Japão, em 1992 e em virtude do aumento de riscos transfusionais, outros países decidiram adotar a conduta, todavia apenas o Brasil, Colômbia e Cuba possuem programas estruturados de hemovigilância e relatam sistematicamente as reações adversas à transfusão. ${ }^{9}$

A abordagem em hemoterapia em especial nos cuidados de enfermagem na prevenção e detecção prévia das RTs e na propagação da importância da prática concretizada em hemovigilância configura-se o impulso de realização desse estudo. 
Deste modo, tornar a aplicabilidade em hemovigilância uma rotina é um fundamento que deve ser intrínseco a todos os profissionais que lidam com o biológico sangue e seus derivados, pois, só assim, estaremos dispondo de fato de uma prática contínua e alerta, que é monitorada, analisada e discutida com a finalidade de total qualidade dos produtos e processos, bem como a nulidade de danos aos profissionais e pacientes envolvidos nessa terapêutica.

\section{OBJETIVO}

Nesse contexto, o presente artigo tem como objetivo relatar as experiências vivenciadas pela acadêmica de enfermagem, durante sua participação, no projeto de extensão com foco em hemovigilância, proporcionado pela Universidade Federal do Rio Grande do Norte.

\section{MÉTODO}

Trata-se de um estudo descritivo, tipo relato de experiência, da participação de uma discente do curso de graduação em enfermagem do $7^{\circ}$ período do Centro Universitário do Rio Grande do Norte em um projeto de extensão intitulado como: Hemovigilância no Complexo Hospitalar da UFRN - Estratégia do Reconhecimento dos Incidentes Transfusionais, criado em 2013, desenvolvido pela Universidade Federal do Rio Grande do Norte - UFRN.

Suas ações são desenvolvidas por uma equipe multidisciplinar, atualmente composta por docentes médicos, enfermeiros, por alunos do curso de enfermagem, medicina, farmácia, por profissionais sensibilizados à proposta do projeto da UFRN e alunos de outras Instituições de Ensino Superior - IES.

Faz-se saber que o complexo hospitalar da UFRN é integrado pelo Hospital Universitário Onofre Lopes- HUOL, a Maternidade Escola Januário Cicco - MEJC, ambas instituições localizadas em Natal e o Hospital Universitário Ana Bezerra HUAB situada em Santa Cruz, mas no momento sem implementação de atividades do projeto. 
A coordenação do projeto está sob responsabilidade de uma enfermeira, Mestre em enfermagem, que assume a Diretoria de Hemovigilância do HUOL. Para que as atividades de extensão também sejam desenvolvidas na MEJC, ela recebe a colaboração de um farmacêutico, membro do comitê transfusional do HUOL e chefe do setor de Vigilância em Saúde da Maternidade Escola Januário Cicco.

\section{RESULTADOS}

\section{DESCRIÇÃO DA EXPERIÊNCIA}

\section{O INÍCIO}

Por acreditar que todo e qualquer atendimento em saúde que preza pela excelência deve estar fundamentado em estudos teóricos e práticos contínuos, tanto para estudantes como para profissionais, a participação em projetos de extensão é uma forma de contemplar essas duas condições.

Assim, a iniciação no Projeto de Extensão em Hemovigilância no Complexo Hospitalar da UFRN - Estratégia do Reconhecimento dos Incidentes Transfusionais ocorreu em 04 de outubro de 2018, motivada pela aquisição de aprofundamento na área de hemoterapia e por compreender a relevância que essa prática tem na qualidade da assistência aos pacientes que dela necessita.

O primeiro encontro do projeto ocorreu com uma recepção do coordenador acadêmico do projeto, que na ocasião explicou todos os objetivos, os locais de atuação, demonstrou como deve proceder a coleta de dados, compilação das informações coletadas e transformação dessas em condutas a serem tomadas para a qualidade dos serviços implementados em hemoterapia, transfusão sanguínea e hemovigilância.

A saber, o projeto se desenvolve com a finalidade de busca permanente na qualidade da assistência em hemoterapia através do fortalecimento da hemovigilância no complexo da UFRN, o projeto se desenvolve buscando por maior integração dos 
alunos da área da saúde em prol da melhoria da hemovigilância no estado do Rio Grande do Norte - RN atendendo às exigências legais do processo de hemovigilância preconizado pela ANVISA.

Para que isso se efetive, com o projeto além da criação de campo de aprendizado em Hemoterapia aos alunos dos cursos de Ciências da Saúde, buscou-se também a promoção de campanhas educativas junto aos pacientes, comunidade acadêmica e profissionais da saúde, ressaltando a importância da doação de sangue; realização de palestras informando os hospitais sobre os dados levantados, possibilitando debates para melhoria do serviço terapêutico e estimulação da notificação dos eventos transfusionais à ANVISA, entre outros.

Quanto ao local da coleta de dados, estabeleceu-se por conveniência para o projeto e para a graduanda em enfermagem, que sua participação/colaboração se daria na MEJC. Sendo assim, seus locais de atuação seria a própria maternidade, para a busca ativa de dados e casos, como também o Núcleo de Hematologia e Hemoterapia- $\mathrm{NHH}$ para apoio e disposição de materiais a serem utilizados.

\section{A SISTEMÁTICA DA COLETA DE DADOS}

Os participantes do projeto responsáveis pelas coletas de dados da MEJC, realizam um fluxo diferente do que é realizado no HUOL. O processo da coleta de dados iniciase pelo deslocamento do participante ao $\mathrm{NHH}$ para realizar o levantamento prévio das transfusões sanguíneas ocorridas na referida maternidade, nas últimas $24 \mathrm{~h}$.

O Núcleo de Hematologia e Hemoterapia, localizado próximo à instituição, se estabelece, dentre outras funções, na perspectiva de apoio, por não existir um banco de sangue responsável pelo armazenamento, distribuição e administração de hemocomponentes dentro da MEJC.

A sistematização, em suma, da coleta até a transfusão de fato se desenvolve após as solicitações prescritas de necessidades de hemotransfusão, em que as amostras de sangue dos pacientes são colhidas em tubos de ensaio e encaminhadas ao núcleo 
para serem feitos testes pré-transfusionais, e só assim as bolsas são dispensadas, em recipiente adequado, para a maternidade e instaladas pela equipe de enfermagem dos setores na MEJC, diferentemente do HUOL que possui uma unidade situada dentro do hospital e profissionais específicos e capacitados periodicamente para desenvolver tais funções.

As informações referentes às transfusões realizadas estão presentes em um livro de registro de liberação de hemocomponentes do $\mathrm{NHH}$, contendo: data da solicitação, número da solicitação feita pelo médico, registro do paciente, nome do paciente para qual foi solicitado, número da bolsa, tipo do hemocomponente, sistema $A B O$, fator $\mathrm{RH}$ do receptor e bolsa e horário de dispensa da mesma. O colaborador repassa estas informações para o caderno de visitas do projeto de extensão de hemovigilância, específico da MEJC, e segue para a maternidade.

$\mathrm{Na}$ maternidade e de posse de informações dos procedimentos transfusionais realizados no dia anterior, o colaborador, por meio de um Aplicativo de Gestão para Hospitais Universitários - AGHU, acessa o prontuário eletrônico dos pacientes internados nesta unidade, este prontuário é alimentado de forma multiprofissional e contém todas as informações relacionadas a assistência de internações anteriores e a atual, com exceção das unidades de terapia intensiva de neonatologia e materna que não contém registros dos profissionais de enfermagem pois ainda são realizados em papel impresso.

Em seguida, é feita a comparação dos dados obtidos no $\mathrm{NHH}$ com os contidos no prontuário, relacionados a TS. É importante confirmar: registro do paciente, nome completo, número de solicitação, o tipo do hemocomponente, número da bolsa, volume, sistema $\mathrm{ABO}$ juntamente com o fator $\mathrm{RH}$ da bolsa e do paciente e registro dos sinais vitais aferidos. Por fim, se houve algum evento adverso, esse também deverá ser registrado no prontuário.

Por último, os dados são lançados em uma planilha categorizada em: data, nome, setor de hemotransfusão, prontuário, paciente gestante, paciente cirúrgico, recémnascido, setor origem do paciente, grupo sanguíneo do hemocomponete e fator $\mathrm{RH}$, 
tipo do hemocomponente, quantidade de hemocomponente transfundido, grupo sanguíneo do receptor, se houve reação transfusional, preenchimento da ficha de notificação, carimbo do plantão médico, carimbo do NHH, notificado pelo NOTIVISA e observações. Nesta planilha ficam registradas todas as visitas, com dados que podem ser utilizados em pesquisas futuras pelos participantes do projeto.

\section{A ENTREVISTA}

Tratando-se do real sentido de execução do projeto, após confirmar todos os dados via prontuário e com a equipe de enfermagem sobre a TS, é indicado e relevante ouvir o paciente, quando possível, sobre a sua experiência com a hemotransfusão, pois, é nesse momento em que muitas vezes consegue-se identificar indícios dos eventos adversos que possam ter ocorrido e passado despercebido, não ter sido valorizado, ou confundido com a sintomatologia da doença de base do paciente.

O projeto, desenvolvido na MEJC, tem, nessa etapa de execução, como alvo a mulher, que pode estar na condição de parturiente; puérpera ou em pós-operatório de cirurgia ginecológica, e o Recém-Nascido - RN. Quando a transfusão ocorre no recémnascido, que por condição própria, ou em mulheres que estejam impossibilitadas de comunicar-se, por estarem internadas na UTI com tratamento de Ventilação Mecânica Invasiva - VMI ou Ventilação Mecânica Não Invasiva - VNI, a continuidade desse processo por meio da entrevista deverá ser contemplada com a equipe assistente à transfusão.

A entrevista é também uma possibilidade de identificar o entendimento dos pacientes e até da própria equipe acerca de características intrínsecas ao procedimento transfusional, em que, por meio das explanações advindas é possível traçar um plano educacional específico e assim estabelecer a educação em saúde e permanente, haja vista que, essas ferramentas são objetivos primordiais desse estudo. 


\section{A REAÇÃO TRANSFUSIONAL}

Durante a entrevista e verificação documental, havendo alguma alteração nos SSVV ou sintomas específicos de uma RT imediata ou tardia é preenchida a Ficha de Notificação e Investigação de Incidentes Transfusionais adverso pelo colaborador, com todas as alterações apresentadas pelo cliente.

Neste momento, é conferido no prontuário do paciente o nome do profissional médico e dos profissionais da equipe de enfermagem que assistiram na estabilização do paciente durante $\mathrm{o}$ incidente transfusional, esses, caso não tenham realizado a notificação, serão contatados, informados sobre a importância de notificação do evento e assim orientados ao registro adequado das informações na ficha.

\section{A INVESTIGAÇÃO, REUNIÕES MENSAIS E A NOTIFICAÇÃO}

Todo o processo de investigação, realizado pelos participantes do projeto, é embasado por estudos prévios, sobre a temática, que dão condições de julgamento sobre as distintas formas de apresentações clínicas, bem como, a verificação de informações sobre o paciente submetido ao tratamento transfusional pelo que consta no prontuário, pelo relato verbal da equipe assistencial, do paciente e acompanhantes, exames laboratoriais e outras fontes de informações primordiais que vão direcionar ou não à reações transfusionais.

Construído o estudo de caso, originado do processo de investigação, inicia-se o preenchimento da Ficha de Notificação de Incidente Transfusional Adverso. Essa ficha e o estudo de caso são levados por todos os participantes que identificaram em suas coletas de dados possíveis RTs, tanto da MEJC como do HUOL, para apresentação e discussão em reunião com todo o grupo. Essas reuniões são realizadas mensalmente e ocorrem no $\mathrm{NHH}$, com datas predefinidas para todo o ano, e havendo necessidade poderão ocorrer de forma extraordinária.

Nesse momento de discussão e análise, é inspirador a riqueza de conhecimentos, a troca, a interdisciplinaridade dos saberes interagindo em busca do melhor assistir em 
hemoterapia. O saber sendo transversal entre teoria e prática para desta forma propiciar a qualidade e apreensão do conhecimento.

Diante de tudo isso, confirmada a RT, notifica-se, caso não, descarta o caso.

\section{ENTRAVES ENCONTRADOS}

Durante a execução das etapas do projeto foram detectados entraves que comprometem todo o processo e merecem atenção afim de encontrar soluções que possam os modificar, e garantir a eficácia das ações desenvolvidas.

Observou-se durante as visitas os seguintes impasses:

- Não disposição do médico que assistiu o paciente durante a reação transfusional;

- Equipe de enfermagem assistente no dia da visita apresentava-se resistente para assinar documentos referente plantão anterior, pois as informações obtidas no dia são sempre referentes as últimas $24 \mathrm{~h}$, como já mencionado anteriormente, inviabilizando o preenchimento da ficha de notificação;

- Ausência de monitoramento dos SSVV antes, durante e após a TS;

- Negligência de registros durante e após a TS inviabilizando a hemovigilância, principalmente se paciente tiver realizado a TS em Centro Cirúrgico;

- $\quad$ não preenchimento da ficha de quando diante de RT;

- Ausência de um Checklist de monitoramento para hemotransfusão e um POP para estabelecer rotina durante o processo.

Assim, na maioria das vezes, as fichas de notificação são preenchidas por enfermeiras do projeto e pelo médico no dia da reunião. Realidade essa que desfavorece o sentido e continuidade da assistência, além de expor o paciente novamente a riscos transfusionais. 


\section{SUGESTÕES DE MELHORIAS}

As sugestões de melhorias se constituem em respostas aos entraves encontrados durante as visitas na MEJC e em situações que podem ser aperfeiçoadas para uma melhor execução do projeto. São elas:

- Aprimoramento dos profissionais e alunos envolvidos tanto no projeto de extensão como dos profissionais que constituem as equipes que assistem os pacientes transfundidos do HUOL e MEJC.

- Nesse caso, os alunos colaboradores receberiam aulas abordando temas essenciais para o desenvolvimento do projeto e aperfeiçoamento da disciplina, elaboradas pelos próprios participantes do projeto durante as reuniões mensais;

- Seriam feitas palestras, para os profissionais de enfermagem, em setores pilotos e posteriormente nos demais setores, abordando os temas: Assistência de Enfermagem Voltada para Hemoterapia, Reações Transfusionais Imediatas e Tardias, e a Importância do Preenchimento da Ficha de Notificação pelos Profissionais na RT. Tendo em vista que a enfermagem está mais próxima do paciente durante todo o ciclo do sangue e tornará mais concreto o processo de hemovigilância destas unidades.

- A criação e implementação de um checklist de Monitoramento Transfusional de sangue que abordasse três das cinco etapas seguras que devem ser executadas corretamente pré, trans e pós-transfusão sanguínea, segundo recomendações da ANVISA com base no Manual técnico de Hemovigilância, 2007. Este foi aprovado pela coordenação do projeto de extensão. Figura.1.

- Criação de um protocolo operacional, implementado em setor piloto e posteriormente para os demais setores, com a finalidade de sistematizar e padronizar a conduta durante a terapêutica.

Neste protocolo seria instituído que o (a) enfermeiro (a) do plantão, no momento da reação transfusional preencheria a ficha de notificação junto com o (a) médico (a) pois desta forma não seria mais necessário procurar em plantões seguintes a equipe 
para assinar a ficha e a mesma seria preenchida de forma fidedigna. $O$ que não dispensaria a entrevista com o paciente pelos alunos do projeto.

Criação e implementação de um fluxograma que indicasse as principais RTs e conduta da equipe de enfermagem, diante da situação, disponibilizado nos setores para melhor conduzir os profissionais.

Figura 1: Checklist de monitoramento transfusional. Natal (RN), Brasil, 2019.

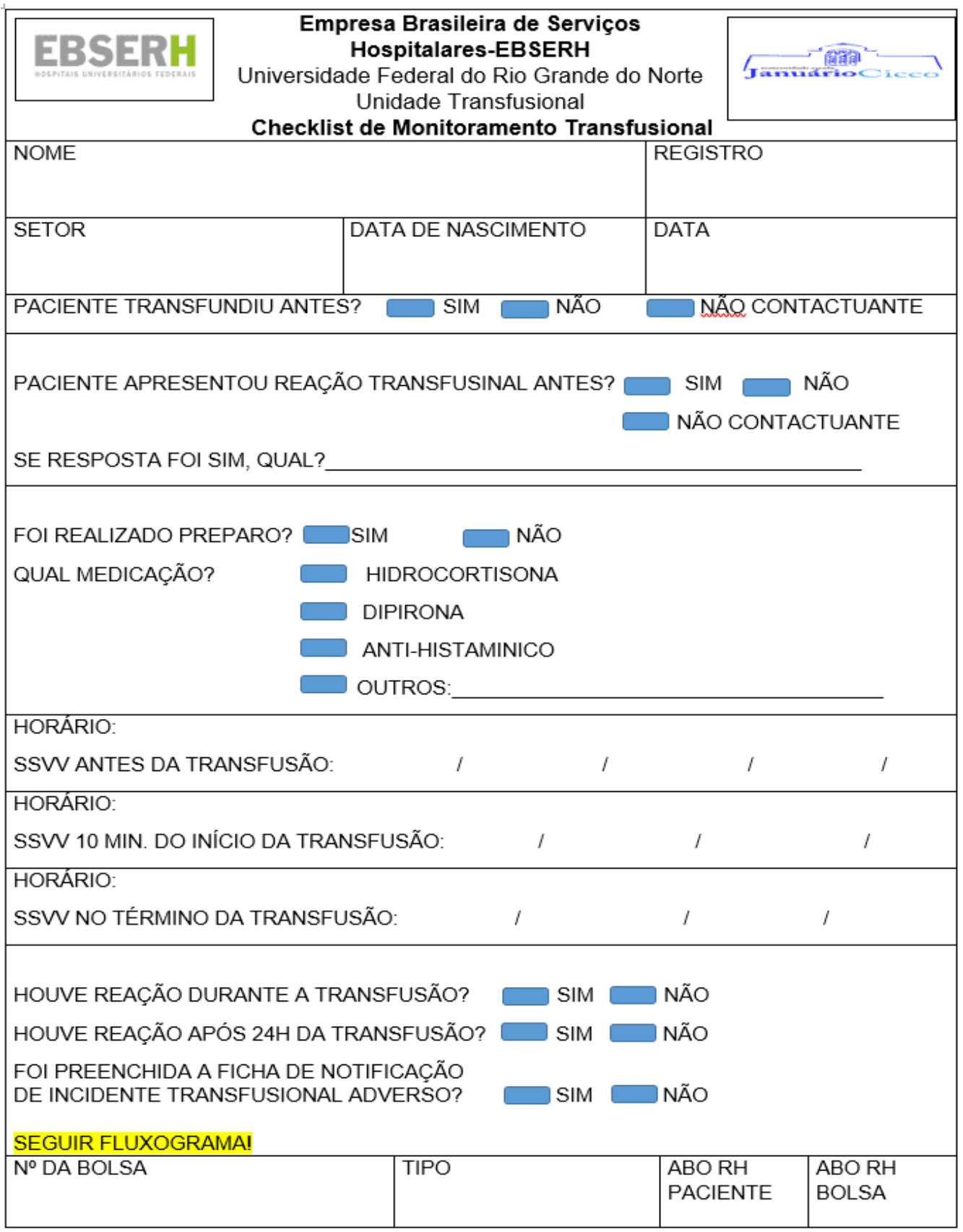

RC: 44471

Disponível em: https://www.nucleodoconhecimento.com.br/saude/hemovigilancia 


\begin{tabular}{|l|l|}
\hline VALIDADE DA BOLSA & PROFISSIONAL RESPONSÁVEL / COREN \\
\hline
\end{tabular}

\begin{tabular}{|c|c|c|c|}
\hline $\mathrm{N}^{0} \mathrm{DA} \mathrm{BOLSA}$ & TIPO & $\begin{array}{l}\text { ABO RH } \\
\text { PACIENTE }\end{array}$ & \begin{tabular}{|l} 
ABO RH \\
BOLSA
\end{tabular} \\
\hline VALIDADE DA BOLSA & PROFISSIONAL RES & & \\
\hline $\mathrm{N}^{0} \mathrm{DA} \mathrm{BOLSA}$ & TIPO & $\begin{array}{l}\text { ABO RH } \\
\text { PACIENTE }\end{array}$ & $\begin{array}{l}\text { ABO RH } \\
\text { BOLSA }\end{array}$ \\
\hline VALIDADE DA BOLSA & PROFISSIONAL RES & & \\
\hline $\mathrm{N}^{0} \mathrm{DA}$ BOLSA & TIPO & $\begin{array}{l}\text { ABO RH } \\
\text { PACIENTE }\end{array}$ & $\begin{array}{l}\text { ABO RH } \\
\text { BOLSA }\end{array}$ \\
\hline VALIDADE DA BOLSA & PROFISSIONAL RES & & \\
\hline $\mathrm{N}^{0} \mathrm{DA}$ BOLSA & TIPO & $\begin{array}{l}\text { ABO RH } \\
\text { PACIENTE }\end{array}$ & \begin{tabular}{|l} 
ABO RH \\
BOLSA
\end{tabular} \\
\hline VALIDADE DA BOLSA & PROFISSIONAL RES & & \\
\hline $\mathrm{N}^{0}$ DA BOLSA & TIPO & $\begin{array}{l}\text { ABO RH } \\
\text { PACIENTE }\end{array}$ & \begin{tabular}{|l} 
ABO RH \\
BOLSA
\end{tabular} \\
\hline VALIDADE DA BOLSA & PROFISSIONAL RES & & \\
\hline $\mathrm{N}^{0}$ DA BOLSA & TIPO & $\begin{array}{l}\text { ABO RH } \\
\text { PACIENTE }\end{array}$ & \begin{tabular}{|l} 
ABO RH \\
BOLSA
\end{tabular} \\
\hline VALIDADE DA BOLSA & PROFISSIONAL RES & & \\
\hline
\end{tabular}

\section{DISCUSSÃO}

As reações transfusionais quando apresentadas durante a infusão são classificadas em imediatas imunes, quando ocorre a reação febril hemolítica e não hemolítica; reação alérgica leve, moderada e grave e Lesão Pulmonar Aguda Relacionada à Transfusão - TRALI, e imediatas não imunes manifestada por contaminação bacteriana; hipotensão por inibidor ECA; sobrecarga de volume; hemólise não imune; embolia aérea; hipotermia e hipocalcemia. ${ }^{10}$ 
Após o período das $24 \mathrm{~h}$, as RTs classificam-se em tardias imunes, caracterizadas por aloimunização eritrocitária; reação enxerto versus hospedeiro; alo imunização plaquetária; púrpura pós-transfusional; imunomodulação e hemólise, e tardias não imunes em que ocorre a hemossiderose e doenças infecciosas. ${ }^{11}$

Com o propósito de promover absoluta segurança desde a coleta, processamento e administração do sangue, bem como orientar boas práticas para serviços de saúde que desenvolvem atividades relacionadas a hemoterapia em todo o território nacional e promover a hemovigilância, que em 11 de junho de 2014 foi regulamentada pela Agência Nacional de Vigilância Sanitária - ANVISA, a Resolução da Diretoria Colegiada- RDC N ${ }^{\circ} 34 .{ }^{7}$

Assim, fica sob observação desse órgão todas as práticas que envolvem o ciclo do sangue, compreendido a partir de um processo sistemático que abrange as atividades de captação e seleção do doador, triagem clínico-epidemiológica, coleta de sangue, triagem laboratorial das amostras de sangue, processamento, armazenamento, transporte, distribuição, procedimentos transfusionais e de Hemovigilância. ${ }^{5}$

Deste modo é necessária, durante todo o clico do sangue, por qualquer profissional de saúde no estabelecimento do ocorrido, a notificação de todas as reações adversas à transfusão por meio da Ficha de Notificação e Investigação de Incidentes Transfusionais disponíveis e confeccionadas pelas unidades de saúde, que deverá ser apurada pelo setor transfusional e repassada à ANVISA, por meio do Sistema de Notificações em Vigilância Sanitária - NOTIVISA ou pelo cidadão, acessando diretamente o NOTIVISA. ${ }^{12}$

Com a finalidade de elucidar a realidade do contexto transfusional no sentido de gerar efetiva apreensão dessa modalidade terapêutica e, por conseguinte sensibilizar sobre, reduzir e/ou eliminar a possibilidade das RTs, a hemovigilância se fundamenta e fortalece o princípio de manutenção da segurança no manejo do ciclo do sangue através de dados publicados no mais recente Relatório de Hemovigilância - Dados consolidados 2002-2015. ${ }^{13}$ 
No relatório é demonstrado que no Brasil, no período de 2002 a 2015, houve um total de 12.841 casos de RTs notificadas, desse total 16\% (2.062) foram da região Nordeste, sendo que no Rio Grande do Norte, de forma decrescente desde 2012, o total em 2015 chegou a 21 notificações. ${ }^{6}$

Figura 2: Tabela de frequência absoluta das notificações de reações transfusionais, por Região e UF, segundo o ano da notificação. Brasil, 2002 a 2014.

Tahela 1: Frequência absoluta das notificaçōes de reaçōes transfusionais, por regiāo e UF, segundo o ano da notificaçĩo. Brasil, 2002 a 2015.

\begin{tabular}{|c|c|c|c|c|c|c|c|c|c|c|c|c|c|c|}
\hline 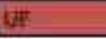 & 20002 & 2001 & 2004 & 2005 & 2005 & 2007 & 2008 & 20009 & 2010 & 2011 & 2012 & 2011 & 2014 & 2015 \\
\hline DF & 0 & 0 & 0 & D & D. & 0 & D & 1. & 60 & 115 & 385 & 209 & 222 & 239 \\
\hline GO & 0 & 0 & 1 & 0 & 0 & 9 & 13 & 6 & 3 & 17 & 81 & 112 & 186 & 240 \\
\hline MS & 0 & 0 & 0 & 6 & 7 & 0 & 0 & 26 & 46 & 26 & 38 & 69 & 39 & 45 \\
\hline MT & 0 & 0 & 0 & D & D & 0 & 0 & 0 & 0 & 13 & 29 & 14 & 22 & 28 \\
\hline $\begin{array}{l}\text { Centro- } \\
\text { Oeste }\end{array}$ & 0 & 0 & 1 & 5 & 7 & 9 & 13 & 33 & 109 & 171 & 533 & 404 & 469 & 552 \\
\hline$A L$ & 0 & 16 & 7 & 8 & 4 & 9 & 11 & 44 & 28 & 30 & 57 & 77 & 51 & 72 \\
\hline$B A$ & 28 & 50 & 34 & 69 & 85 & 83 & 150 & 226 & 367 & 351 : & 421 & 496 & 477 & 538 \\
\hline $\mathrm{CE}$ & 1 & 54 & 24 & 32 & 76 & 217 & 113 & 107 & 359 & 565 & 413 & 415 & 574 & 661 \\
\hline MA & 0 & 0 & 0 & 4 & 3 & 25 & 31 & 41 & 67 & 35 & 185 & 145 & 139 & 115 \\
\hline$P B$ & 0 & 3 & 0 & 0 & 0 & 0 & 17 & 22 & 108 & 138 & 124 & 97 & 105 & 111 \\
\hline PE & 0 & 0 & 12 & 6 & 0 & 5 & 43 & 91 & 57 & 155 & 110 & 205 & 334 & 383 \\
\hline PI & 0 & D & 0 & o & 0 & 0 & 0 & 0 & 0 & 1 & 59 & 55 & 45 & 68 \\
\hline $\mathrm{RN}$ & 0 & 1 & 0 & D & D & D & D & 3 & 6 & 6 & 33 & 41 & 29 & 21 \\
\hline SE & 0 & 0 & 0 & D & 0 & 0 & 0 & 0 & 0 & 12 & 22 & 37 & 37 & 93. \\
\hline Nondeste & 29 & 124 & $\pi$ & 119 & 169 & 339 & 365 & 534 & 992 & 1295 & 1424 & 1568 & 1791 & 2062 \\
\hline$A C$ & 4 & 10 & 6 & 9 & 5 & 1 & 3 & 6 & 22 & 22 & 20 & 27 & 32 & 26 \\
\hline AP & 0 & 0 & 0 & D & 0 & 0 & 4 & D & 0 & 0 & 0 & 0 & 6 & 0 \\
\hline AM & 0 & 0 & 0 & D & 0 & 40 & 31 & 33 & 9 & 30 & 101 & 77 & 96 & 115 \\
\hline PA & 0 & 7 & 3 & 12 & 6 & 11 & 67 & 35 & 104 & 366 & 254 & 181 & 169 & 139 \\
\hline FO & 0 & 0 & D & D & D. & 8 & 30 & 12 & 6 & 17 & 29 & 58 & 67 & 114 \\
\hline FR & 0 & 0 & 0 & D & 0 & 0 & Q & 0 & 1 & D & 0 & o & 28 & 56 \\
\hline TO & a & 0 & D & D & D & 0 & 0 & 2 & 0 & 13 & 14 & 2 & 40. & 31. \\
\hline Norte & 4 & 17 & 9 & 21 & 11 & 60 & 135 & 83 & 142 & 448 & 418 & 345 & 438 & 481 \\
\hline ES & 0 & 0 & 0 & D & 0 & 0 & 32 & 23 & 21 & so & 159 & 197 & 289 & 757 \\
\hline MG & 2 & 4 & 17 & D & 0 & 26 & 53 & 93 & 61 & 173 & 188 & -315 & 312 & 729 \\
\hline हल) & 59 & 54 & 5ा & 140 & 118 & 157 & 270 & 247 & 293 & 312 & 861 & 1173 & 1178 & 1126 \\
\hline SP & 24 & 98 & 438 & 777 & 585 & BD6: & 1212 & 1603 & 1845 & 2536 & 3306 & 3831 & 4424 & 4852 \\
\hline Sudeste & 85 & 256 & 512 & 917 & 703 & g89 & 1567 & 1956 & 2220 & 3271 & 4514 & 5515 & 6203 & 7064 \\
\hline$P R$ & 41 & 173 & 186 & 171 & 204 & 120 & 246 & 341 & 326 & 382 & 558 & 658 & 734 & 976 \\
\hline RS & 1 & 184 & 57 & 60 & 20 & 133 & 212 & 338 & 46.6 & 661 & 715 & 871 & 1071 & 1062 \\
\hline$s c$ & 0 & 11 & 29 & 139 & 75 & 141 & 75 & 216 & 342 & 306 & 410 & 472 & 541 & 644 \\
\hline 5 ul & 42 & 368 & 272 & 370 & 299 & 394 & 533 & 895 & 1134 & 1349 & 1683 & 2001 & 2346 & 2682 \\
\hline Liratil & 1 tail & 565 & E11 & 1433 & 11199 & 1791 & 2013 & 3516 & 4597 & I5318 & 8572 & 9834 & 11397 & 12941 \\
\hline
\end{tabular}

BRASIL, 2015, p.15.

Esses dados revelam a não incorporação da jurisprudência que determina as notificações de reações transfusionais nos Estabelecimentos Assistenciais de Saúde - EAS no Brasil, cooperaram para a vulnerabilidade do processo transfusional e 
consequente aumento das reações aos hemocomponentes transfundidos que ficarão ocultados, expandido as subnotificações e os riscos à saúde da população envolvida nos processos transfusionais, seja doadora ou receptora. ${ }^{7}$

Diante do exposto, o checklist foi um documento elaborado, pela graduanda, baseado nas orientações da ANVISA, como resultado da vivência no projeto de extensão, com a finalidade de contribuir, orientar e padronizar as práticas infusionais, dos profissionais de enfermagem e corroborar para novos estudos/pesquisas. É a complementaridade dos conhecimentos teóricos com os práticos na indução rotineira e constante de investigação das RTs, além de se constituir garantia na segurança assistencial e no fortalecimento da acurácia profissional.

Portanto o checklist já é um mecanismo utilizado em instituições de saúde que primam pela conformidade de seus serviços, assim, nada mais apropriado de incorporar como meta no sentido de garantir a melhoria sistematizada nos cuidados, assegurando o assistir sem riscos. ${ }^{14}$

"O uso do checklist denota a necessidade de haverem materiais escritos de apoio à tomada de decisão em hospitais que assegurem aos enfermeiros - que detêm a responsabilidade legal pelo ato transfusional - a diminuição dos erros de omissão e a variação nos cuidados prestados" 14:2.

Concernente à assistência de enfermagem, estudos que tinham como principal objetivo a avaliação do conhecimento da equipe de enfermagem sobre o processo transfusional, observaram que a TS é um procedimento de alta complexidade e que existe uma fragilidade no conhecimento dos profissionais diante da hemoterapia decorrente da deficiência do conteúdo durante a graduação, números reduzidos de pós- graduação lato sensu voltados para esta área, bem como a falta de treinamentos no ambiente de trabalho que aborde este conteúdo, protocolos, fluxogramas e de avaliações periódicas sobre a manutenção da assistência preconizada. ${ }^{15-17}$ 
Por consequência, um estudo comparativo realizado em um hospital do estado de Nova York, entre a quantidade de notificações de supostas reações transfusionais, realizadas por enfermeiros, em setores pediátricos e adultos, ficou evidenciado que embora o número total de notificações geradas pelos profissionais de ambos os setores não foram significativamente diferentes, identificou-se a necessidade de uma educação voltada para o reconhecimento dos sintomas das reações tranfusionais, pois os mesmos confundiram em muitos casos reações relacionadas a gravidade da doença com um evento adverso relacionado à transfusão. Afirmando que a enfermagem requer uma compreensão mais profunda sobre a temática abordada. ${ }^{18}$

No intuito de garantir qualidade da assistência de enfermagem em todos os contextos concernentes ao ciclo do sangue, os enfermeiros devem atentar para a continuidade da manutenção efetiva da prestabilidade dos serviços de hemoterapia e hemovigilância nos EAS. E a Educação em Saúde se constitui ferramenta de alta incontestabilidade para o enfermeiro propagar os preceitos transfusionais à sua equipe, e com isso garantir uma assistência que vai ao encontro da ética, perícia e prudência, livre de prejuízos aos pacientes. ${ }^{19}$

\section{CONCLUSÃO}

O presente estudo nos permite compreender que a equipe de enfermagem desenvolve um papel importante na ordenação do ciclo do sangue, estando envolvida da doação até a hemotransfusão. Em vista disso, por estar nos cuidados constantemente com o paciente e ter conhecimento da sintomatologia clínica que o mesmo apresenta, pode, por meio de conhecimento técnico e científico, identificar alterações hemodinâmicas que possam presumir reações transfusionais. Por este motivo, é de suma importância que estes profissionais estejam capacitados para garantir que a hemovigilância aconteça.

Deste modo, com os conhecimentos adquiridos após o início das atividades desenvolvidas no projeto de extensão, foi possível observar que para a efetivação de suas propostas nas questões concernentes à prevenção e identificações de RTs, e por conseguinte o assistir seguro para todos os envolvidos nesse processo, sejam 
profissionais, doadores e receptores, é imperioso uma revisão na grade curricular dos cursos de graduação em enfermagem e pós-graduação Lato-sensu e Stricto-sensu, de forma que se consolide a abordagem em hemoterapia e hemovigilância como componentes curriculares, incluindo-os não apenas como conteúdo e sim como disciplina.

Constatou-se a deficiência na sistematização da assistência de enfermagem diante da hemoterapia, no que tange à hemovigilância, ficando suas atividades destinadas à instalação, remoção das bolsas transfusionais, e quando diante de intercorrências, a reversão dos sinais, sintomas e sem a observância de relatos inerentes à transfusão nas evoluções de enfermagem.

O ambiente de trabalho também se constitui lugar de aprendizagem e melhoramento. Sendo assim, prover educação permanente em hemoterapia e hemovigilância bem como discutir a sua importância como terapêutica indispensável à prática clínica nos cuidados em saúde, torna-se uma conduta eficiente que propiciará uma assistência de qualidade, livre de riscos e danos.

A construção de uma política de desenvolvimento instrucional atendendo as recomendações da ANVISA, a realização de treinamentos periódicos, checklist, fluxogramas, criação de protocolos operacionais, entre outros, para que se tenha um trabalho em que todos estejam conscientes de sua responsabilidade na prevenção, redução e intervenção resolutiva diante de reações transfusionais, consolidando o seu papel na equipe multiprofissional de hemovigilância.

\section{REFERÊNCIAS}

1. Carneiro VSM, Barp M, Coelho MA. Hemoterapia e reações transfusionais imediatas: atuação e conhecimento de uma equipe de enfermagem. REME rev. Min. Enferm. [internet] 2017. [acesso em 2019 mar 12]; 21:e-1031. Disponível em: http://ww w.reme.org.br/artigo/de tal hes/1167. 
2. Pereira CS, Franco CS, Monteiro MGS, Rodrigues AMU, Abreu RNDC. Cuidados de enfermagem para segurança do paciente em hemoterapia. Rev. Enferm. UFPI. 2016. [internet]. [acesso em 2019 jan 2]; Jan-Mar;5(1):28-33. Disponível em: http://www. ojs.ufpi.br/index.p hp/reufpi/article/view/5002/pdf.

3. Ministério da Saúde (BR). Agência Nacional de Vigilância Sanitária- ANVISA. Hemovigilância: Manual Técnico Para Investigação Das Reações Transfusionais Imediatas e Tardias Não Infecciosas. Brasília: Ministério, 2007 [Internet]. [acesso em: 2019 fev 15].

Disponível em: http://www.cvs.saude.sp.gov.br/zip/manual_tecnico_hemovigilancia081 12007.pdf.

4. Barbosa HB, Nicola AL. Enfermagem na Terapia Transfusional e Hemovilância: análise da conformidade em um hospital de ensino. Saúde (Santa Maria) [internet]. 2014 [acesso em 2019 mar 24]; Vol. 40, n. 2, jul/dez, p. 97-104,2014. Disponível em: https $</ /$ period icos.ufsm.br/revistasaude/ article/view/13074.

5. Grandi JL, Grell MC, Areco KCN, Barbosa DA. Hemovigilância: a experiência da notificação de reações transfusionais em hospital universitário. Rev. esc. enferm. USP. [Internet]. 2018 [acesso em: 2019 nov 07]; 52: e 03331. Disponível em: http://www.s cielo.br/scielo.phpscript=sci_arttext\&pid=S00806234201800010043 $1 \& \operatorname{lng}=$ en.

6. Resoluções Conselho Federal de Enfermagem (Brasil). Resolução ํㅜ 511, de 29 de março de 2016. Aprova a norma técnica que dispõe sobre a atuação de enfermeiros e técnicos de enfermagem em Hemoterapia [Internet]. Diário Oficial da União 4 abr 2016 [acesso em: 2019 mar 21]. Disponível em: http://www.cofen.gov.br/resoluc aocofen-no-05112016 39095.html.

7. Resoluções Agência Nacional de Vigilância Sanitária (Brasil). Resolução n 34, de 11 de junho de 2014. Dispõe sobre as boas práticas no ciclo do sangue [Internet]. Diário Oficial da União 16 jun 2014 [acesso em: 2019 mar 24]. Disponível em: http://portal.anvisa. 
gov.br/documents/10181/2867975/RDC_34_2014_COMP.pdf/283a192e-eee8-42cc8f06-b5e5597b16bd?version=1.0

8. Martínez MA, Rivero JRA, Fernández DN. Efectos adversos en la cadena transfusional en el Instituto de hematología e inmunología. Rev. Cuba. Hematol. Inmunol. Hemoter. [Internet]. 2015 Sep [citado 2019 Nov 19]; 31(3): 288-300. Disponible en: http://scielo.sld.cu/scielo.php?script=sci_arttext\&pid=S086402892015000300007.

9. Silva BHM, Bencomo HA, Díaz AB, Rodriguez BZ, Castañeda GC, Ballester SJM. Resultados de un programa de hemovigilancia. Rev. Cuba. Hematol. Inmunol. Hemoter. [Internet]. 2018 Jun [citado 2019 Nov 19]; 34(2): 131-142. Disponible en: http://scielo.sld.cu/scielo.php?script=sci_arttext\&pid=S0864-02892018000200004.

10. Hofacker D, Tavares KCJ, Silva, LG, Souza RS. Reconhecimento das reações transfusionais imediatas: protocolo de intervenções de enfermagem segundo taxonomia NIC. Revista EDUC-Faculdade de Duque de Caxias [internet]. 2018. [acesso em: 2019 mar 21]; Vol. 05- № 2/jul/dez. Disponível em: http://uniesp.edu.br/sites/_bibliot eca/revistas/20190731162301.pdf.

11. Ministério da Saúde (Brasil). Secretaria de Atenção à Saúde. Departamento de Atenção Especializada e Temática. Guia para uso de hemocomponentes. Brasília: Ministério da Saúde,2015 [Internet]. [acesso em: 2019 mar 16]. Disponível em: http://bvsms.saude.gov.br/bvs/publicacoes/guia_uso_hemocomponentes_2ed.pdf.

12. Covo MZ. Matriz de recomendações para melhoria do desempenho do ciclo do sangue do no hemocentro coordenador do estado do Paraná. Paraná. Dissertação [Mestrado Profissional em Enfermagem] - Universidade Federal do Paraná; 2018 [internet]. [Acesso em: 2019 abr 12]. Disponível em: https://acervodigital.ufpr.br/bitstream/handle/1884 /59402/R\%20\%20D\%20\%20MAGALI\%20ZIMMERMANN\%20COVO.pdfsequence=1 \&isAllowed $=\mathrm{y}$. 
13. Santos LKBAL. O uso das tecnologias digitais para o ensino em hemoterapia: construção e validação de um material didático para um curso a distância. Natal. Dissertação [Mestrado em Inovação em Tecnologias Educacionais] - Universidade Federal do Rio Grande do Norte; 2019 [internet]. [Acesso em: 2019 out 21]. Disponível em:

$<$ https://repositorio.ufrn.br/jspui/bitstream/123456789/26754/1/Usotecnologiasdigitais _Santos_2018.pdf>.

14. Bezerra CM, Cardoso MVLML, Silva GRF, Rodrigues EC. Construção e validação de checklist para transfusão sanguínea em crianças. Rev Bras Enferm [Internet]. 2018. [acesso em: 2019 maio 28]; 71(6):3196-202. Disponível em: http://www.scielo. $\mathrm{br} / \mathrm{pdf} / \mathrm{reben} / \mathrm{v} 71 \mathrm{n} 6 / \mathrm{pt}$ 0034-7167-reben-71-06-3020.pdf.

15. Jardim T, Ramos VLS, Blásius FR, Silva EL, Bonomini FG. Transfusões de sangue - o conhecimento dos profissionais de enfermagem. Rev. enferm. UFPE online. [internet]. 2014. [acesso em: 2019 abr 12]; 8(6):1649-57. Disponível em: https://periodicos.ufpe.b r/revistas/revistaenfermagem/article/view /13637/16490.

16. Tavares JL, Barichello E, Mattia L, Barbosa MH. Fatores associados ao conhecimento da equipe de enfermagem de um hospital de ensino sobre hemotransfusão. Rev. Latinoam. Enferm. (online). [internet]. 2015. [acesso em: 2019 abr 12]; 23(4):595-602. Disponível em: http://www.scielo.br/pdf/rlae/v23n4/pt_01041169-rlae-23-04-00595.pdf.

17. Amaral JHS, Nunes RLS, Rodrigues LMS, Braz MR, Balbino CM, Silvino ZR.Hemoterapia: um desafio no cotidiano da equipe de enfermagem. Rev. enferm. UFPE on line. [inetrnet]. 2016. [acesso em: 2019 abr 05]; 10(Supl. 6):4820-7. Disponível em: https://periodicos.

Ufpe.br/revistas/revistaenfermagem/article/viewFile/11261/1288.

18. Vossoughi S, Parker-Jones S, Schwartz J, Stotler B. Provider trends in paediatric and adult transfusion reaction reporting. [internet]. Vox Sang. 2019 Abr [acesso em: 2019 Nov 18]; 114 (3): 232-236. doi: https://doi.org/10.1111/vox.12758 
19. Tiburcio MP. Simulação realística como estratégia de ensino aprendizagem no processo transfusional. Natal. Tese [Doutorado em Enfermagem] - Universidade Federal do Rio Grande do Norte; 2017 [internet]. [acesso em: 2019 mar. 20]. Disponível em: https://repositorio.ufrn.br/jspui/bitstream/123456789/25075/1/ManuelaPintoTib urcio_TESE.pdf. Grandi JL, Grell MC, Areco KCN, Barbosa DA.

Enviado: Dezembro, 2019.

Aprovado: Janeiro, 2020. 